\title{
CONGENITAL DEFORMITIES IN THE SUDAN \\ 5. CRANIOFACIAL DEFORMITIES AND COCCYGEAL AGENESIS IN ANOMALOUS BOVINE CALF
}

\author{
HIND E. OSMAN*; Y. SHUAIB* , Z.H. IBRAHIM* \\ *: Sudan University for Science and Technology, College of Veterinary Medicine
}

\section{ABSTRACT}

Received at: 27/11/2012

Accepted: 10/1/2013
A description is given to a cross bred female calf with multiple congenital deformities. The animal had muscloskletal deformities and recumbent since birth. It had no tail (coccygeal agenesis) and exhibited multiple facial deformities. Postmortem examination of the body revealed collapsed areas in the lung and yellowish discoloration of the liver, intestine and cortex of the kidneys. Congested foci were manifested in the liver.

Key words: Key words: congenital deformities, coccygeal agenesis, hypotelorism, microphthamia, muscloskletal deformities.

\section{INTRODUCTION}

With the increase in number of big farms, cross breeding, using of selected breeding sires and/ or artificial insemination, congenital deformities arise as one of the alerting pathological conditions. They are defined as abnormalities in structure or function that are present at birth (Rahman et al., 2006). Many of the reported cases were craniofacial including: aprosopia (Dennis and Leipold, 1972), diprosopia (Osman Hind and Khaleel, 2004 and Osman Hind et al., 2007), dicephalus (Gawlikowski, and Misinakewicz, 1979; Mcgirr et al., 1987; Gruys, 1973 and Wakuri et al., 1990), wry face (LaRue, 1997), hypotelorism (Cho et al., 1985). cyclopia (Gawlikowski, 1993; Hirooka and Hamana, 1999; Schulze and Distl, 2006 and Ozcan, et al., 2006), microphthalmia (Chlmers, and Rocken, 1990), agnathia (Dennis and Liepold, 1972), brachygnathia (Heidari et al., 1985 and Schalles et al., 2012) and cheilognathoschisis (Loeffler, 1990 and Moritomo et al., 1999). Other defects which were rarely reported are the coccygeal agenesis and deformed coccygeal vertebrae (Behrens et al., 1993; Gulbahar et al., 2009 and Anwar and Purohit, 2012).

Reporting of congenital deformities will increase the clinical and pathological knowledge of them; it also helps identifying the ones of genetic origin and subsequently the carrier breeds or breeding sires as a first steps for reducing the incidence (Gentile, and Testoni, 2006). This report describes and illustrates a case of multiple craniofacial malformations accompanied with coccygeal agenesis in a cross-bred bovine calf, and to the best of our knowledge, it is the first scientific report of this combination of defects in the same calf in the Sudan.

\section{CASE REPORT}

An alive female, cross-bred bovine calf with several congenital deformities (Fig. 1) was submitted to the clinic of the College of Veterinary Medicine and Animal Production, Sudan University for Science and Technology. The dam and sire of the affected calf were raised in Mahlab no. 2, Hilat Koko, Khartoum North (Nile East). The apparently normal dam gave several normal births and then the deformed calf with a known inbreeding.

The full-term deformed calf was clinically examined five hours after birth. The animal had normal bawling and was found to be alert. The fore limbs of the deformed calf were thickened and more rounded than normal. The recumbent since birth animal showed difficulty in standing, but when anteriorly supported, she could stand on the hind limbs. The animal was slightly smaller in size than normal; its height from the hoof of the fore limb to the first thoracic vertebra was $54 \mathrm{~cm}$ (normal is about $54 \mathrm{~cm}$ ) and the length from the anal region to the first thoracic vertebra was $67 \mathrm{~cm}$ (normal is about $71 \mathrm{~cm}$ ) $\mathrm{cm}$. The animal had no tail (tailessness) and exhibited an anal opening which was placed slightly higher than normal. The Temperature of the deformed animal was $40.9^{\circ} \mathrm{C}$, respiratory rate was 70 cycle per minute, femoral pulsation and heart rate were uncountable.

The deformed-face length and width were 15 and 13 $\mathrm{cm}$ respectively (the normal is about 22 and $15.5 \mathrm{~cm}$ ). 
The animal exhibited mild hypotelorithm. The two eyes were different in size. They showed asymmetry and apparent microphthalmia (Fig. 2); the left eye was $1 \times 3 \mathrm{~cm}$ in size with closed palpebral tissue and with no obvious orbit, it was at a distance of 3.5 (normal is about $5 \mathrm{~cm}$ ) $\mathrm{cm}$ from the median line of the face and $10 \mathrm{~cm}$ from the base of the ear; and the right was $0 \times 2 \mathrm{~cm}$ in size with a deformed orbit, it was at a distance of $5 \mathrm{~cm}$ from the median line of the face and $7 \mathrm{~cm}$ from the base of the right ear. The dentition was normal. The animal had no nasal openings and a lateral cleft in the upper lip (cheiloschisis). The tongue was protruding with tapered end (Fig. 2). There was concomitant movement in the tracheal area and the cheeks during inspiration and expiration. The animal had laboured abdominal breathing, severe tachycardia and obvious muscle spasm in the neck.
The animal was euthanized due to invalidism and difficulty to survive. Post-mortem examination of the body was done nine hours after birth and revealed collapsed areas in the lung. The collapsed areas constituted about one sixth of the right lung and less than that ratio in the left one; the rest of the two lungs had pale colour. There were yellowish discoloration of the liver, intestine and cortex of the kidneys. No growth abnormality was detected in the diaphragm and trachea but the latter was hyperaemic. Congested foci were manifested in the liver. The heart showed no apparent deformity.

Histopathological results revealed atelactatic and emphysematous areas in the lung and focal hyperaemia in the liver.

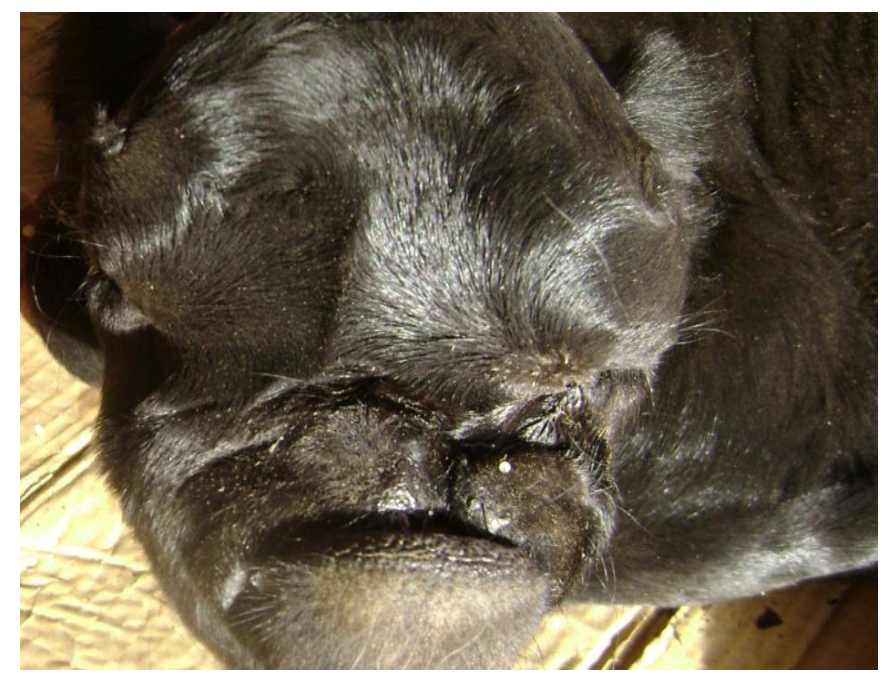

Fig. 1: Facial deformities in anomalous cross-bred bovine calf

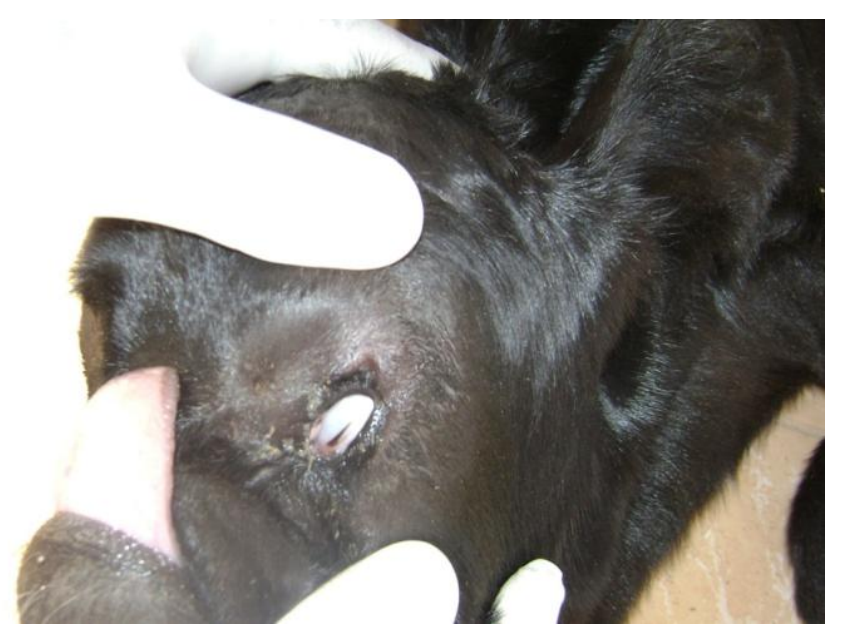

Fig. 2: Multiple facial deformities: Protruding tongue with tapered end, Microphthalmia and deformed eye orbit. 


\section{DISCUSSION}

Congenital defects cause economic losses by increasing prenatal calve mortality, decreasing maternal productivity, and decreasing the value of a defective calve (invalidism and death). They are not infrequent in the Sudan. However, proper documentation of these cases seems to be lacking in the whole country till 1998.

Microphthalmia in bovine was reported before in the Sudan by (Osman Hind and Khaleel, 2004), but in the present anomalous calf it was accompanied with hypotelorism which coincide with the report of Gawlikowski (1993). Other craniofacial malformations such as deformed upper jaw and nasal area (Osman Hind, 2011) were also recorded before in Nile East, Khartoum, Sudan.

This report is the first documentation of coccygeal agenesis, hypotelorism, microphthalmia, and cleft lip in the same bovine calf in the Sudan.

As recorded by Newman et al. (1999) multiple malformations may occur as a result of a malformation of one portion of the body directly leads to malformation of others.

Kim et al. (2007) reported a defective sacrocaudal agenesis and difficulty in standing in a native Korean calf in which there is absence of caudal vertebrae starting from the fifth lumber vertebra which is accompanied with atresia ani. The calf in the present report had an anal opening which is only misplaced. She was unable to stand, and had coccygeal agenesis but the lumber and sacral vertebrae were present although the length of the trunk of the animal is slightly shorter than normal. The fore limbs were the obvious affected ones and are suggested to be the cause of recumbence in this case.

The cleft lip was due to failure of closure in facial processes that form the jaw and face during embryonic development (Vijayanand et al., 2009). Loeffler (1990) and (Moritomo et al., 1999) studied the clefts of the lip in bovine. It is found to be median, lateral, or bilateral and with or without cleft palate (Moritomo et al., 1999). In the present case there is no cleft palate and the cleft of the lip was a lateral one. Cleft lip was reported in combination with locomotory disorders (Vijayanand et al., 2009). The later defect was reported by Kim et al. (2007) in combination with a defective anal opening. In this deformed case the cleft lip was also found with locomotory disorder and a misplaced anal opening whereas in the case reported by Noh et al. (2003) the anal opening was closed.

The causes of anomalies are not fully known (Kutsi et al., 2003) but many factors may have a role in such cases include environmental factors (Gentile and Testoni, 2006; Staffenberg et al., 2002), genetic mutations (Noh et al., 2003; Staffenberg et al., 2002) and biological factors (Moritomo et al., 1999).

Although the deformities of that calf were not seen in any of the previous calves of the dam, a cow at the same area- Mahlab No.2 showed coccygeal agenesis. As inbreeding was practiced in the farms of Mahlab no. 2 for several decades; the producers in that area used to share one breeding bull in several farms for many years, genetic relationship between the two cases is possible. Still, lack of records in the farm and illiteracy of the owner besides that it was a sporadic case make it difficult to know the exact cause.

\section{REFERENCES}

Anwar, S. and Purohit, G.N. (2012): Rare congenital absence of tail (anury) and anus (atresia ani) in male camel (Camelus dromedaries) calf. Open Veterinary Journal. 2: 69-71.

Behrens, C.; Kuczka, A. and Geunert, E. (1993): An unusual combination of different organ anomalies and skeletal abnormalities in a black and white calf. Tierarztl Prax, 1993: 21 (3): 185-187.

Chlmers, A.G.; Rocken, L. (1990): A congenital defect resembling Hereford syndrome I in Alberta. Can Vet J 31: 31-33.

Cho, D. -Y.; Zeman, D.H. and Miller, J.E. (1985): Holoprosencephaly in a bovine calf. Acta Neuropathologica. 673-4): 322-325.

Dennis, S. and Liepold, H. (1972): Agnathia in sheep: external observations. Am. J. Vet. Res. 33: 339-347.

Dennis, S.M. and Leipold, H.W. (1972): Aprosopia (facelessness) in lambs. Veterinary Records. 90: 13, 365-7.

Gawlikowski, J. (1993): Cyclopia in a case report. Zeszyty Naukowe Akademia Rolniczej. W. Szczencinie Zootechnika. 29: 63-69.

Gawlikowski, J. and Misinakewicz, A. (1979): Studies on congenital deformities in cattle. XXVIII. A dicephalic calf (dicephalus bicollis). Zeszyty Naukowe Akademia Rolniczej. W. Szczencinie Zootechnika. 15: 101-109.

Gentile, A. and Testoni, S. (2006): Inherited disorders of cattle: a selected review. Slov vet res. 43 (1): 17-29.

Gruys, E. (1973): Dicephalus, Spina bifida, ArnoldChiari malformation and duplication of thoracic organs in a calf. Discription of the case and critical discussion of the pathogenesis of Arnold-Chiari malformation. Zentralblatt fur Veterinary Medizin. 10(20A): 789-800.

Gulbahar, M.Y.; Kabak, M.; Yarim, M.; Guvenc, T. and Kabak, Y.B. (2009): Persistent cloaca fused kidneys, female pseudohermaphroditism 
and skeletal anomalies in a in simmintal calf. Anat Histol Embryol, 2009, 38 (3): 229232.

Heidari, M.; Vogt, DW. and Nelson, SL. (1985): Brachygnathia in a herd of Angus cattle. Am J. Vet. Res. 46(3): 708-10.

Hind Osman, E. (2011): Wry face in a cross bred bovine calf. Assiut Veterinary Medical Journal. 57 (128): 234-240.

Hind Osman, E. and Khaleel, O. (2004): A case of diprosopia in a bovine calf, Sudan J. Vet. Sc. Anim. Husb. 43: 1-2, 239-243.

Hind Osman, E.; Badawi, M.N.; Musa, M.B.; Hala Ali, M. and Rabab Ahmed, M. (2007): A Case of Diprosopia in Anomalus Cross-Bred Bovine Calf. Veterinary research. 1(3): 61-64.

Hirooka, M. and Hamana, K. (1999): Three cases of cyclopia. Japan Veterinary medical Association. 52(10): 644-647.

Kim, C.S.; Koh, P.O.; Cho, J.H.; Park, O.S.; Cho, K.W.; KIM, G.S. and Won, C.K. (2007): Sacrocaudal agenesis in a Korean native calf (Bos Taurus Coreanae). J. Vet. Med. Sci. 69 (6): 653-655.

Kutsi, K.; Cantay, G.; Yelda, D. and Can, K.N. (2003): CT and MR Imaging Findings of a Rare Craniofacial Malformation: Diprosopus. A. J. R. 180: 863-864.

LaRue, W. (1997): Wry face in camelides. Alpaca Registry Journal. 2: 27-31.

Loeffler, K. (1990): Lip-jaw split in a calf. Comments on the article, "Cornea dermoids and double malformations of the nares in a calf," by $\mathrm{C}$. Neophytou] Berl Munch Tierarztl Wochenschr. 103(9): 297-298.

Mcgirr, W.; Partlow, G. and Fisher, K. (1987): Two headed two necked twin calf with partial duplication of thoracoabdominal structures role of blastocyst hatching. Anat Rec. 217(2): 196-202.

Moritomo, Y.; Tsuda T. and Miyamoyo, H. (1999): Craniofacial skeletal abnormalities in Anomalus calf with clefts of the face. J. Vet. Med. Sci. 61(10): 1147-52.
Moritomo, Y.; Tsuda, T. and Miyamoto, H. (1999): Craniofacial skeletal abnormalities in anomalus calf with clefts of the face. J. Vet. Med. Sci. 61(10): 1147-1152.

Newman, S.J.; Baily, T.L.; Johnes, J.C.; WiGrassie, W.A. and Whittier, W.D. (1999): Multiple congenital anomalies in a calf. J. Vet. Diag. Invest. 11: 368-371.

Noh, D.H.; Jeong, W.I.; Lee, C.Y.; Chung, J.Y.; Jee, Y.H.; Do, S.H.; An, M.Y.; Kwon, O.D.; Williams, B.H. and Jeong, K.S. (2003): Multiple congenital malformation in a Holstein calf. J Comp. Pathol. 129 (4): 313315.

Ozcan, K.; Gurbulak, K.; Takci, I.; Ozen, H. and Kacar, C. (2006): Atypical cyclopia in a new Swiss cross calf: a case report. Anat Histol Embryol. 35(3): 152-154.

Rahman, M.M.; Khan, M.S.I.; Biswas, D.; Sultradhar, B.C. and Saifuddin, A.K.M. (2006): Pygomelia or supernumerary limbs in a crossbred calf. J. Vet. Sci. 7 (3): 303-305.

Schalles, R.R.; Leipold, H.W. and McCraw, R.L. Beef cattle handbook (BCH 1900): www. Iowabeef center.org/retrieved on $2^{\text {nd }}$ October 2012.

Schulze, U. and Distl, O. (2006): Case report: arthinia and cyclopia in a German Fleckvieh calf. Dtsch Tierarztl Wochenscher. 133(6): 236239.

Staffenberg, W.; Mulliken, J. and Shanske, E. (2002): Diprosopia: A unique cases and review of literature. Teratology. 66: 282-287.

Vijayanand, V.; Gokulakrishnan, M. and Rajasundaram, R.C. (2009): Multiple congenital defects in a new born calf- A case report. Tamilnadu J. Veterinary and Animal Sciences. 5(4): 161-163.

Wakuri, M.; Mori, T. and Mutoh, K. (1990): Arnoldchiari malformation and associated anomalies in a dicephalic newborn calf. Okajimas Flia. Anat. Jpn. 67(5): 339-350. 